Archivum, LXX (I), 2020, pp. 147-164

\title{
Una propuesta sobre la creatividad literaria desde la Teoría de la Literatura y la Neurociencia
}

\author{
Luis Martínez-FaLero \\ Universidad Complutense de MAdrid \\ lmartinezfalero@filol.ucm.es
}

Recibido: 09/07/2019

Aceptado: 21/10/2019

\section{RESUMEN:}

En este trabajo se plantea una vía novedosa para el estudio de la creatividad literaria, desde la Neurociencia y la Teoría de la Literatura, con algunas consideraciones de antropología cultural, a través de una formulación interdisciplinar. Con ello, se busca formular unas bases sólidas en el terreno de la Teoría de la Literatura. En esta propuesta se pretende analizar sucintamente, por una parte, la incidencia de la institución literaria y la creación de imágenes mentales, como elementos esenciales para la creatividad poética, así como el papel de la memoria, capacidad humana que articula el proceso creador, mediante la formulación lingüistica de las imágenes mentales y el conocimiento de las convenciones procedentes de la institución literaria. A ello, habría que unir la cuestión de la adscripción de una forma determinada a un contenido determinado, a través de la ejercitación (para la adquisición de la técnica) y la intuición para que dicha adscripción se produzca de manera automática.

PALABRAS CLAVE: Neurociencia, Teoría de la Literatura, creatividad, antropología poética. 
A proposal on literary creativity from the Theory of Literature and Neuroscience

\begin{abstract}
:
In this paper, a novel way is proposed for the study of literary creativity, from the Neuroscience and the Theory of Literature, with some considerations about cultural anthropology, through an interdisciplinary formulation. With this, we seek to formulate solid foundations in the field of Literary Theory. This proposal aims to analyze succinctly, on the one hand, the incidence of the literary institution and the creation of mental images, as essential elements for poetic creativity, as well as the role of memory, human capacity that articulates the creative process, through the linguistic formulation of the mental images and the knowledge of the conventions coming from the literary institution. To this, it would be necessary to unite the question of the ascription of a determined form to a determined content, through the exercise (to acquire the literary technique) and the intuition so that this ascription occurs automatically.
\end{abstract}

KEY WORDS: Neuroscience, Theory of Literature, creativity, anthropological poetics.

Si hablamos de la aplicación de la neurociencia a los estudios sobre literatura, tal vez con una cierta hipérbole, podríamos decir: "En el principio fue Mark Turner". O quizá no se trate de una hipérbole, sino de la constatación del impresionante impacto internacional que obtuvo su libro The Literary Mind (1996), dando pie, por una parte, a sustentar teóricamente la existencia de una "mente literaria"; y, por otra, a replantear los modos de representación (mental y textual) que el profesor norteamericano había expuesto al afirmar que nuestro pensamiento actúa a través de "parábolas" (por tanto, de modo literario) respecto de la experiencia cotidiana (Turner, 1996; 1999; 2002). Por tanto, esta actividad 'literaria' sería previa a la adquisición de una gramática e incluso sería la base de la competencia lingüística, como anteriormente se había venido afirmado desde los postulados idealistas de Giambattista Vico (1995, 228-229) o de Benedetto Croce (1969).

Como es sabido, la revista Poetics Today dedicó a este planteamiento cognitivo sendos números monográficos en años conse- 
cutivos $(2002 ; 2003)$, en los que se recogían varias de las críticas a Turner, centrando buena parte del debate en la cuestión de si era posible aplicar los estudios de neurociencia en el ámbito de las Humanidades (Van Oort, 2003). Los avances en las neurociencias y los posteriores trabajos para su aplicación en la actividad artística (y su recepción) han cubierto esos vacíos y han permitido aplicar sus conclusiones, siempre susceptibles de ampliación o rectificación.

En primer lugar, el proceso de comunicación literaria ha sido entendido, desde el punto de vista de la ciencia cognitiva, como un paso necesario para desembocar en una transdisciplinariedad ineludible para los estudios sobre literatura, de tal manera que, tanto la teoría de la literatura (en general) como los estudios sobre recepción (en particular), se justifiquen y alcancen un mayor grado de rigor científico (Crane y Richardson, 1999; Burke, 2013). Pero, si asumimos el estudio de manera transdisciplinar, no solo debemos aceptar unos principios psicológicos procedentes del cognitivismo, que nos den cuenta de la creación y recepción del texto o de cualquier obra artística (sea de la naturaleza que sea), una vez superados los modelos freudianos y en buena parte también los junguianos (en los estudios de Ciencia Cognitiva de la Literatura se ha mantenido en muchas ocasiones el concepto de 'arquetipo' y sus dimensiones simbólicas); sino que será necesario mantener y matizar las propuestas teórico-críticas procedentes del ámbito filológico, así como una necesaria contextualización antropológica para poder definir cada uno de los componentes que intervienen en la comunicación literaria. Estas bases antropológicas se constituyen en una cuestión esencial, desde el momento en que nos muestran las estructuras culturales y sociales en que se ha generado un texto determinado y se ha producido su recepción, lo que, sin duda, determina la comprensión por parte de los lectores o de los oyentes. Pero también la interactuación entre el individuo y la cultura en que se inscribe, así como la interactuación entre individuos en una sociedad (cultura) determinada (Sperber, 
1988, 177), de tal modo que la unión de las distintas caras de este prisma desemboque en un estudio semiótico de carácter cognitivo; es decir, en una semiótica cognitiva a través de la cual cada producto cultural pueda ser conocido e interpretado de modo científicamente riguroso.

Así, la teoría cognitiva se ha venido aplicando a la interpretación de textos (Caracciolo, 2016), pero también ha dado lugar a la neuroestética, donde, partiendo de presupuestos teóricos clásicos, se desemboca en el análisis del gusto mediante la práctica clínica neurológica que permite determinar en qué áreas y de qué modo (placer/indiferencia/desagrado) se produce la recepción de una obra (Livet, 2005; Starr, 2013, 21-67).

Decíamos que en muchas ocasiones se parte de presupuestos teóricos clásicos: no es extraño encontrar en los trabajos de neuroestética una reflexión inicial sobre el concepto de 'imaginación ${ }^{1}$ de acuerdo con la preceptiva clásica (Platón, Aristóteles), como hallamos en el libro Feeling Beauty (2013) de G. Gabrielle Starr. Ello nos lleva a considerar la necesidad de justificar o de reformular algunos preceptos procedentes de la (historia de la) teoría y de la crítica de la literatura, desde el momento en que la neurociencia nos ha proporcionado sólidos principios de certeza para esta justificación o esta reformulación. Todo ello, desde luego, ha de encuadrarse en el seno de una Poética Cognitiva que también ha alcanzado un amplio desarrollo en los últimos años (Tsur, 1992; Stockwell, 2002; Harrison y Stockwell, 2014).

Quizá el ámbito de estudio que ha gozado de mayor atención más recientemente ha sido el de la creatividad, tanto científica como artística. Buena prueba de ello es la aparición de tres manuales en muy corto espacio de tiempo: Neuroscience of creativity (2013, editado por Oshin Vartanian, Adam S. Bristol y James C. Kaufman), The Cambridge Handbook of the Neuroscience of Creativity (2018, editado por Rex E. Jung y Oshin Vartanian) y The Neuroscience of Creativity (2018, de Anna Abraham). Los

1 Para una trayectoria de los conceptos de 'imaginación' y de 'creatividad poética' desde Platón al siglo xx: Martínez-Falero, 2006. 
dos primeros manuales, aun con la pretensión de inscribir buena parte de su contenido en la neuroestética (de ahí la presencia de Oshin Vartanian), inciden sobre todo en cuestiones referentes a la psicopatología y a los efectos de determinadas sustancias en el cerebro, asociado todo ello a la creación artística. En nuestro contexto de estudio, los voy a dejar al margen.

En el caso del manual de Anna Abraham, no solo encontramos una puesta al día de las cuestiones referentes a la creatividad en la ciencia y las artes, sino un completo desglose de cómo actúa la creatividad en cada una de las artes, lo que nos permite conocer mejor los diferentes aspectos de la creación de objetos estéticos en pintura, escultura, arquitectura y literatura (poesía y narrativa). Por ello quisiera comenzar con Anna Abraham una aproximación a la definición de creatividad, objeto de este trabajo.

Para esta psicóloga británica, la creatividad se encuentra entre la novedad y la adecuación del hallazgo. Siguiendo a Runco y Jaeger, considera que consiste en

una idea que era nueva de alguna manera. De hecho, este es el atributo principal que define la creatividad. Para que una idea sea considerada creativa debe ser original o novedosa. La originalidad es lo que hace que una idea sea única o inusual en comparación con otras ideas que emergen en un momento dado [...].

Si bien la originalidad es el factor central para determinar el grado de creatividad asociado con una idea, no es el único factor necesario. Un segundo componente en cuestión es el de la adecuación, relevancia o ajuste [...].

Con esto, tenemos los dos elementos centrales de la creatividad [...], a saber, que una idea creativa es aquella que se considera original y apropiada dentro de un contexto particular. (Abraham, 2018, 30-31)

En esta definición estándar de la creatividad, la originalidad ocupa un lugar destacado, al tiempo que - respecto de los ele- 
mentos considerados tanto en lo referente a la originalidad como a esa pertinencia o adecuación (Runco y Jaeger, 2012, 92) - existe una jerarquía en la creatividad, considerando como variables tanto los elementos implicados en la delimitación de esta definición estándar (Abraham, 2018, 106) como los propuestos por Robert Sternberg y Todd Lubart $(1986 ; 1991 ; 1995)$ como componentes de la creatividad: motivación, inteligencia, personalidad, estilos de pensamiento, conocimiento y entorno (Kaufman, 2002), de los que el entorno - tras la práctica clínica correspondiente- resulta el menos determinante.

En este sentido, cabría trazar un paralelismo entre esta jerarquía de la creatividad y la definición de 'talento' y de 'genio' en la Estética de Hegel. Si, para el filósofo alemán, el talento es innato, el genio, por su parte, "es la capacidad general para la verdadera producción de la obra de arte, así como la energía para la ideación y actualización de la misma" (Hegel, 1989-I, 246). Hegel, como cumbre del Romanticismo estético, ${ }^{2}$ está uniendo en su concepción tanto la originalidad respecto del enfoque de los contenidos (que asume como miméticos, pero reformulados por la subjetividad, tanto en lo perceptivo como en una flexibilidad de las formas) $)^{3}$ como la habilidad técnica que permite que el artista o el escritor ofrezca una forma novedosa.

Tras esta breve cala en la consideración de la creatividad por parte de Hegel, resulta evidente que este concepto viene ya marcado por su trayectoria histórica, en cuanto a qué elementos lo configuran: originalidad/pertinencia (o adecuación) y habilidad técnica marcarían así la pauta para determinar esa jerarquía ha-

2 Este concepto de 'genio' llega al Romanticismo a través de Kant, quien afirma en el §46 de la Crítica del juicio (1790): “Genio es el talento (dote natural) que da la regla al arte. Como el talento mismo, en cuanto es una facultad innata productora del artista, pertenece a la naturaleza, podríamos expresarnos así: genio es la capacidad natural innata (ingenium) mediante la cual la naturaleza da la regla al arte" (Kant, 1989, 213).

3 Recordemos que, por ejemplo, las poéticas tanto del paradigma clásico como del clasicista (que alcanza hasta el Romanticismo) eran no solo descriptivas, sino también prescriptivas. 
cia la que apuntaban diversos neurocientíficos. En realidad, nos hallamos ante dos conceptos fundamentales de la poética clásica, de amplia trayectoria teórico-crítica a lo largo de la historia de la teoría de la literatura, debidos a Horacio: la creatividad vendría determinada por la dicotomía ingenium/ars (vv. 295-346 del Ars poetica); es decir, por unas condiciones innatas para la creación y por una habilidad técnica que permita al artifex desarrollar su obra.

Mi intención en las siguientes líneas es la de actualizar estos conceptos horacianos en el contexto de una Ciencia Cognitiva Literaria, a la luz de las aportaciones de las diferentes ciencias involucradas en la cuestión de la creación literaria, en esa simbiosis que ha de desembocar en el necesario conocimiento científico de la literatura, de acuerdo con las bases del cognitivismo aplicadas a la cultura (y, en ella, a la literatura), pero también en lo que la literatura (a través de ese conocimiento científico) puede aportar a las neurociencias (Troscianko y Burke, 2017).

Para ello, debemos partir de las estructuras antropológicas en que se inscribe la producción literaria, ya que el autor dispone de un dispositivo simbólico procedente de la sociedad que le sirve como marco en el que se forma y se ha desarrollado cognitivamente, de tal modo que va a determinar no solo su visión (imagen) del mundo, sino también su interpretación, lo que alcanza a la recepción de objetos artísticos. Así, afirma Dan Sperber:

Adquirir un dispositivo simbólico conforme a la cultura en que se vive no consiste, pues, en sólo tratar simbólicamente materiales de esta cultura, sino en tratar materiales de orígenes diversos de una manera culturalmente determinada. Cabe solamente imaginar que algunos materiales orientan de modo decisivo la construcción del dispositivo simbólico y aseguran entre los miembros de una misma cultura una homogeneidad relativa a este enfoque. (1988, 115) 
Pero el sujeto no actúa de manera pasiva respecto de este dispositivo simbólico (y de las convenciones que indican la adecuación de su empleo), sino que puede transformarlo o ampliarlo a través de esa creatividad que permite hallar nuevas técnicas o modificar las convenciones existentes y que ha recibido como herencia cultural de su entorno. Es aquí donde encontraríamos la retroalimentación del imaginario colectivo y del imaginario individual, pues los cambios o ampliaciones pasarían a ese dispositivo simbólico común o a convertirse en nueva convención junto a las anteriores una vez aceptadas por la comunidad cultural.

Esta percepción individual del mundo y de los objetos artísticos (cuyo soporte son esas estructuras antropológicas compartidas por una sociedad) suponen una abstracción de los objetos (Abraham, 2018, 134), que, en el terreno de la literatura, determina que el lector pone en juego su experiencia del mundo (tanto su experiencia vital como sus percepciones o sus lecturas previas), llevando a cabo una reconstrucción del texto en la imaginación (Troscianko, 2013), íntimamente ligada a la memoria desde los mismos orígenes teóricos de la creatividad. Es decir, la imaginación consiste en una ficción (re)creada a partir de los referentes almacenados en la memoria; frente a la fantasía, concebida como la generación de unos referentes emancipados de la memoria, aunque con un número suficiente de referentes 'reales' para que el mundo creado resulte comprensible para el lector. Ello nos conduce, por una parte, hacia una "lectura implícita" a través de la cual el lector deduce, de manera no consciente, una posibilidad de significado que produce un determinado sentimiento, de acuerdo con la propuesta de Antonio Damasio (Damasio, 2010, 87-102; Hayles, 2014, 205), que en buena medida viene a entroncar con la teoría desarrollada por Roman Ingarden en La obra de arte literaria (1983, primera edición en alemán de 1931), desde la fenomenología. Pero también deduce las convenciones de cada género y los actantes que conforman los textos, en una actividad consciente e inconsciente, lo que configura una "memoria textual", de acuerdo con lo expuesto por Daniel Dubuisson en su Anthropologie poétique (1996): 
Gracias a su memoria textual, progresivamente enriquecida, gracias a la función textual, que no cesa de trabajar este patrimonio inmaterial, gracias también a su competencia de 'lector' de textos, el individuo se construye una cosmografía, es decir, el universo en el que se inscribe su ser, su nombre y sus actividades. $(1996,36)$

De este modo, la memoria articula tanto las imágenes mentales, como fuente de la creatividad (lo que ha sido demostrado experimentalmente por LeBoutillier y Marks, 2003) y una tradición cultural (en este caso, literaria) deducida por medio de la práctica de la lectura, hasta configurar una memoria textual que da forma a la ficción en la imaginación. Como señala Jean-Pierre Changeux, la variabilidad de la actividad epigenética ocupa un lugar central en esta generación de nuevas imágenes:

El acceso a la conciencia, en la que los recuerdos evocados ocupan un lugar central, es un proceso neurológico que comienza a ser comprendido, pero que aún requiere un mejor conocimiento de sus bases neuronales y de su génesis a través de la relación del individuo con su entorno físico, social y cultural y su historia personal única. Es fundamentalmente un 'proceso endógeno'. La actividad espontánea del sistema nervioso ha sido postulada durante mucho tiempo como un mecanismo crítico de la epigénesis de la red neuronal y de los procesos descendentes que tienen lugar en el espacio de un trabajo neuronal global. (Changeux, 2011, 68)

Pero estas imágenes, si hablamos de creatividad literaria, han de transformarse en secuencias lingüísticas. Ello supone, en primer lugar, una no correspondencia exacta entre la imagen visual y las imágenes verbales que pueden ser expresadas (Suler y Rizziello, 1987). Existe, por tanto, un grado de diferencia entre lo imaginado y lo expresado verbalmente. No obstante, para esta actividad de transformación de la imagen mental en imagen verbal, el cerebro humano interconecta diversas áreas durante el proceso de creación, tal como se ha venido describiendo 
(Alexandrov, 2007) y demostró experimentalmente (en lo referente a poemas) Siyuan Liu y su equipo: la generación de un poema se caracterizaría por "un patrón disociado", produciendo un aumento de actividad en el córtex prefontal, que se extendería desde el polo frontal al área dorsolateral de la corteza prefrontal, activándose también el surco intraparietal y la precuña, así como el surco temporal y otras áreas relacionadas con el lenguaje, con una conexión con la amígdala (área cerebral asociada a los sentimientos), entre otras áreas cerebrales que intervienen en el proceso creador (Liu et al., 2015). Esta actividad cerebral ha sido confirmada por Roger E. Beaty, Paul J. Silvia y Mathias Benedek (2017) al trabajar sobre la dimensión cognitiva de la metáfora a través del empleo de la neuroimagen, relacionando la producción de metáforas con otras formas de la cognición autogenerada y dirigida hacia objetivos.

Toda esta interacción entre diferentes áreas cerebrales, con la interconexión entre la memoria a largo plazo (MLP) y la memoria a corto plazo (MCP), se traduce en la actividad creativa, al establecerse una relación necesaria entre imagen mental e imagen verbal, no entendida como un símbolo de la palabra, sino como un contenido semántico (Howes y O'Shea, 2014, 201), por lo que esta descripción de procesos cognitivos desemboca en un mensaje, que, en el caso que nos ocupa, consistiría en un objeto estético de naturaleza lingüística. Este contenido semántico, a la hora de concretarse en el texto, puede transformarse en un lenguaje figurado (es decir, se puede transformar en diversas figuras y tropos), así como puede ser sometido a un estilo particular en sus diferentes niveles de construcción (Burke, 2013). Sabemos que el empleo de figuras y tropos posee una naturaleza cognitiva y constituye un universal antropológico (Arduini, 2000, 131-157).

Si en el caso del texto narrativo la complejidad de las operaciones cognitivas ha sido destacada en varios estudios (Boyd, 2009; Kormos y Trebits, 2012; Abraham, 2018, 344-370), la cuestión del texto poético y, sobre todo, la producción de textos imaginistas (los textos literarios más alejados del habla común) nos 
plantean la conexión entre la creatividad (definida en términos de originalidad y adecuación, como capacidad humana innata que coincide con los rasgos fundamentales de la concepción clásica del ingenium) y la habilidad técnica (ars) en cuanto al procedimiento creativo orientado a la construcción textual, sea de naturaleza narrativa, sea de naturaleza poética.

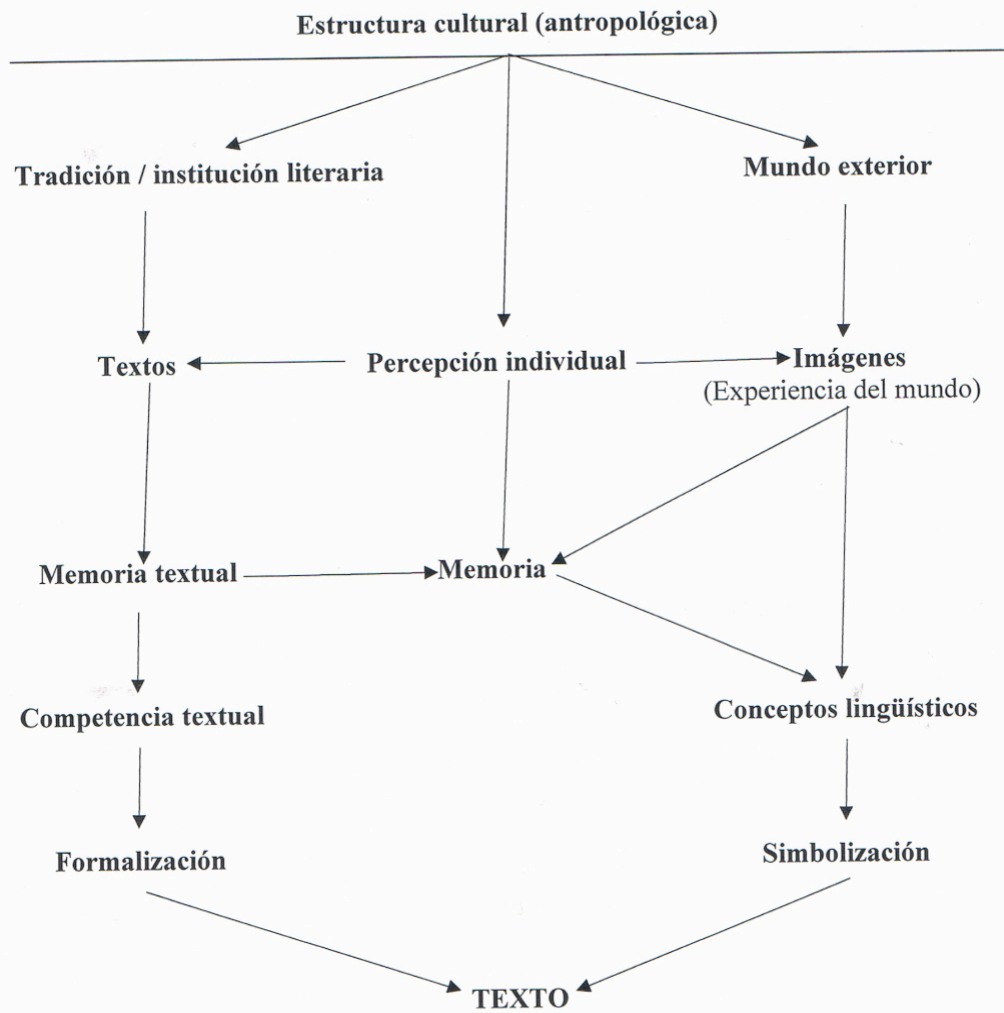

Bases cognitivas de la creatividad literaria

Esta habilidad técnica (ars, techné), a la que hemos venido aludiendo a lo largo de este trabajo, procede de ese conocimiento no consciente de las convenciones formales, genéricas, temáticas, etc., que configuran una determinada tradición literaria (como 
parte de la tradición cultural). Proceden, por tanto, de esa "memoria textual" de la que hablaba Daniel Dubuisson, y que se explicita en el plano consciente de la creación literaria. Junto a ella, la ejercitación se convierte en un elemento fundamental para que el contenido semántico abstracto alcance el carácter de objeto estético de naturaleza literaria. La ejercitación viene ya formulada por Quintiliano en su Institutio oratoria (2.17.5) como requisito para que el orador domine el arte de la elocuencia. Pero también ha de serlo en el caso de la creación literaria. A través de la ejercitación, el escritor (sea en prosa o en verso) aprende a construir textos en el género literario elegido, unida al ingenio o creatividad. Ambos planos, como se ve, resultan (ya desde la preceptiva clásica) necesarios para que el texto posea carácter de objeto estético. Una vez que el autor adquiere esa 'competencia creativa', le asigna una forma a ese contenido semántico abstracto. Si la deducción de las formas se ha producido de manera no consciente, en tanto que el escritor es primero lector, esta asignación de las formas a unos contenidos abstractos se efectuará en un proceso inconsciente y consciente (al seleccionar y/o corregir los actantes textuales nacidos en la imaginación), es decir, a través de un conocimiento intuitivo que la memoria textual y la ejercitación han puesto a punto. En palabras de Gerd Gigerenzer, estas reacciones instintivas constan de "simples reglas generales que sacan provecho de facultades evolucionadas del cerebro" $(2008,27)$. De este modo, una intuición concebida como manifestación de una serie de habilidades ejercitadas se convierte en la explicitación de un ars que actúa ante una situación de nueva experiencia (la escritura literaria como metaexperiencia creativa). Así, respecto de las experiencias cotidianas, señala Gigerenzer:

Una regla automática está adaptada a nuestro entorno del pasado sin que medie una evaluación presente sobre si es adecuada. Simplemente se produce cuando aparece un estímulo. La vida se ha basado en esta forma de mecanismo desde tiempo inmemorial. Las reglas flexibles, en cambio, conllevan una evaluación rápida sobre 
cuál utilizar. Si una no funciona, hay otras entre las que elegir. La expresión 'inteligencia del inconsciente' se refiere a este proceso rápido de evaluación; según ciertas neuroimágenes cerebrales, podría estar relacionada con la corteza frontal intermedia anterior [...]. Las reacciones instintivas quizá parezcan simplistas, pero su inteligencia subyacente reside en seleccionar la regla general correcta para cada situación. $(2008,59)$

Esta misma actividad puede ser trasladada a la creación de un texto como experiencia existencial.

El caso extremo, decíamos, de esta dicotomía establecida por la posibilidad de crear y la habilidad técnica, lo hemos indicado en la poesía imaginista. En este caso, este proceso extremo creativo (habida cuenta de que la originalidad de las imágenes, su novedad a lo largo de cada poema de cada libro de cada autor es una condición sine qua non para considerarla 'arte') supone una evidente ruptura de las reglas de la gramática. Si existe una gramática particular para la literatura (que, desde un punto de vista generativo, ha sido estudiada - por ejemplo- por Teun A. van Dijk [1971; 1972]), esta, en el caso de este tipo de poesía, posee unos procedimientos creativos que tienen como consecuencia la aparición de subcategorizaciones anómalas ${ }^{4} \mathrm{o}$ de la asociación de palabras por su repetición y/o por su relación de analogía o de contigüidad, sea en el plano fónico, en el sintáctico o en el semántico, lo que supone un procedimiento creativo a través de patrones compositivos que corresponden a patrones mentales de asociación. Ese contenido semántico, por tanto, se manifiesta en forma de texto en un lenguaje más allá del lenguaje, con una gramática que rompe las reglas gramaticales, con una forma que trasmite un contenido abriendo su interpretación a la capacidad de sugerencia en el lector (u oyente) al resonar más que al decir.

Así, por ejemplo, en el siguiente poema de Blanca Andreu podemos encontrar varios de estos procedimientos:

$4 \mathrm{El}$ concepto de 'subcategorización' fue establecido por Noam Chomsky en el capítulo cuarto de sus Aspects of the Theory of Syntax (2014; 157-206). 
Extraño no decirlo y hablar hidras pensadas

o hacer poesía y cálculo,

extraño no contarte que el cianuro Cioran viene sobre las diez,

o viene Rilke el poeta

a contarme que sí, que de veras tú pasas a mi sangre

pero de qué nos sirve.

Veneno y sombra extraña, extraño no decirlo, de metales muy fríos y faltos de latido:

amor, es eso, yo bebo violas rotas,

pienso cosas quebradas,

en verdad yo me bebo la infancia del coñac,

bebo las locas ramas virginales,

bebo mis venas que se adormecen para querer morir,

bebo lo que me resta cuando dejo mi cuello

bajo la luna de guillotina,

bebo la sábana de los sacrificios y bebo el amor que salpica sueño pero de qué nos sirve. (Andreu, 1986, 33)

Así, hallamos subcategorizaciones anómalas ("hablar hidras pensadas", "bebo las locas ramas virginales", etc.), atracción fónica ("cianuro Cioran"), paralelismo (todas las secuencias que comienzan con "bebo" en la segunda parte del poema), etc., lo que orienta la expresión del poema a través de una sucesión de imágenes hacia una significación determinada, como manifestación de la destreza técnica y de la creatividad de la autora. Capacidad creativa y habilidad técnica como medio de comunicación, como experiencia profunda, como capacidad de sugerencia para producir un efecto (cognitivo) en el lector o en el oyente.

A lo largo de este estudio he pretendido renovar y justificar en su formulación clásica y en su reescritura más actual dos conceptos fundamentes de la tradición poética y de la teoría de la literatura. Esta actualización supone un mayor conocimiento de nuestra naturaleza, aun cuando queda mucho por explorar en neurociencia y también mucho por investigar en la Ciencia 
Cognitiva Literaria. En todo momento he pretendido mantener el debido rigor científico que este nuevo ámbito de conocimiento requiere. Nuevas vías se abren en nuestro campo de estudio, nuevas formas de interpretación y de comprensión del arte, de la literatura, de nuestra sociedad y, sobre todo, del ser humano.

\section{Referencias bibliográficas}

Abraham, A. (2018) The neuroscience of creativity, Cambridge / Nueva York, Cambridge University Press.

Alexandrov, V. E. (2007) "Literature, Literariness, and the Brain", Comparative Literature, 59, 2, 97-118.

Andreu, B. (1986) De una niña de provincias que se vino a vivir en un Chagall, Madrid, Hiperión.

Arduini, S. (2000) Prolegómenos a una teoría general de las figuras, Murcia, Universidad de Murcia.

Beaty, R. E., Silvia, P. J. y Benedek, M. (2017) “Brain network underlying novel metaphor productions", Brain and Cognition, 111, 163-170.

Boyn, B. (2009) On the Origin of Stories. Evolution, Cognition and Fiction, Cambridge (MA), Harvard University Press.

Burke, M. (2013) “The rhetorical neuroscience of style: On the primacy of style elements during literary discourse processing", Journal of Literary Semantics, 42, 2, 199-215.

Caracciolo, M. (2016) "Cognitive Literary Studies and the Status of Interpretation: An Attempt at Conceptual Mapping", New Literary History, 47, 3, 187-208.

Changeux, J.-P. (2011) “The Epigenetic Variability of Memory: Brain Plasticity and Artistic Creation", en Nalbantian, S., Matthews, P. M. y McClelland, J. L. (eds.), The Memory Process. Neuroscientific and Humanist Perspectives, London, The MIT Press, 55-72.

Сномsкy, N. (2014) Aspects of the Theory of Syntax, Cambridge (MA) / London, The MIT Press.

Crane, M. Th. y Richardson, A. (1999) “Literary Studies and Cognitive Science: Toward a New Interdisciplinarity", Mosaic, $32,2,123-137$. 
Croce, B. (1969) Estética como ciencia de la expresión y lingüística general, Buenos Aires, Nueva Visión.

Damasio, A. (2010) Self Comes to Mind. Constructing the Conscious Brain, Nueva York, Pantheon Books.

Dubuisson, D. (1996) Anthropologie Poétique. Esquisses pour une anthropologie du texte, Louvain-la-Neuve, Peeters.

Gigerenzer, G. (2008) Decisiones instintivas. La inteligencia del inconsciente, Barcelona, Círculo de Lectores.

Harrison, C. y Stockwell, P. (2014) "Cognitive poetics", en Taylor, J. R. y Littlemore, J. (eds.). The Bloomsbury Companion to Cognitive Linguistics, Londres, Bloomsbury, 218-233.

Hayles, N. K. (2014) "Cognitive Everywhere: The Rise of the Cognitive Nonconscious and the Costs of Consciousness", New Literary History, 45, 2, 199-220.

Hegel, G. W. F. (1989) Estética, Barcelona, Ediciones Península, 2 vols.

Horacio Flaco, Q. (1996) Sátiras. Epístolas. Arte poética, Madrid, Cátedra.

Howes, M. B. y O'Shea, G. (2014) Human Memory. A Constructivist View, San Diego (CA), Elsevier.

INGARDEN, R. (1983) L'œuvre d'art littéraire, Lausanne, L'Âge d'Homme.

Jung, R. E. y Varnatian, O. (eds.) (2018) The Cambridge Handbook of the Neuroscience of Creativity, Cambridge, Cambridge University Press.

Kant, I. (1989) Crítica del juicio, Madrid, Espasa-Calpe.

Kaufman, J. C. (2002) "Dissecting the Golden Goose: Components of Studying Creative Writers", Creativity Research Journal, 14, 1, 27-40.

Kormos, J. y Trebits, A. (2012) “The Role of Task Complexity, Modality, and Aptitude in Narrative Task Performance", Language Learning. A Journal of Research in Language Studies, 62, 2, 439-472.

LeBoutillier, N. y Marks, D. F. (2003) "Mental imagery and creativity: A meta-analytic review study", British Journal of Psychology, 94, 1, 29-44. 
Liu, S., Erkkinen, M. G., Healey, M. L., Xu, Y., Swett, K. E., Chow, H. M.y Braun, A. R (2015) “Brain Activity and Connectivity During Poetry Composition: Toward a Multidimensional Model of the Creative Process", Human Brain Mapping, 36, 9, 3351-3372.

Livet, P. (2005) "Les émotions esthétiques", en Borillo, M. (ed.), Approches cognitives de la création artistique, Liège, Mardaga, 11-30.

Martínez-Falero, L. (2006) "Poesía y creatividad: introducción a una poética de la creación", Dicenda. Cuadernos de Filología Hispánica, 24, 161-179.

Poetics Today (2002) 23, 1.

Poetics Today (2003) 24, 2.

Quintiliano, M. F. (1971) Institutionis oratoriæ libri XII, ed. L. Radermacher, Leipzig, Teubner, 2 vols.

Runco, M. A. y Jaeger, G. J. (2012) “The Standard Definition of Creativity", Creative Research Journal, 24, 1, 92-96.

Sperber, D. (1988) El simbolismo en general, Barcelona, Anthropos.

Starr, G. G. (2013) Feeling Beauty. The Neuroscience of Aesthetic Experience, Cambridge (MA), The MIT Press.

Sternberg, R. J. y Lubart, T. I. (1986) "Investing in creativity", American Psychologist, 51, 7, 677-688.

Sternberg, R. J. y Lubart, T. I. (1991) “An investment theory of creativity and its development", Human Development, 34, 1, 1-32.

SternberG, R. J. y Lubart, T. I. (1995) Defying the crowd. Cultivating creativity in a culture of conformity, Nueva York, Free Press.

Stockwell, P. (2002) Cognitive Poetics. An introduction, Londres / Nueva York, Routledge.

Suler, J. R. y Rizziello, J. (1987) "Imagery and Verbal Processes in Creativity", The Journal of Creativity Behaviour, 21, 1, 1-6.

Troscianko, E. T. (2013) "Reading imaginatively: The imagination in cognitive science and cognitive literary studies", Journal of Literary Semantics, 42, 2, 181-198. 
Troscianko, E. T. y Burke, M. (2017) "Introduction: A Window on to the Landscape of Cognitive Literary Science", en Burke, M. y Troscianko, E. T. (eds.), Cognitive Literary Science. Dialogues between Literature and Cognition, Nueva York, Oxford University Press, 1-13.

Tsur, R. (1992) Toward a Theory of Cognitive Poetics, Ámsterdam, North Holland.

Turner, M. (1996) The Literary Mind. The Origins of Thought and Language, Nueva York, Oxford University Press.

Turner, M. (1999) "A Mechanism of Creativity", Poetics Today, 20, 3, 397-418.

Turner, M. (2002) "The Cognitive Study of Art, Language, and Literature", Poetics Today, 23, 1, 9-20.

Van Dijk, T. A. (1971) "Some Problems of Generative Poetics", Poetics, 1, 2, 5-35.

VAn DijK, T. A. (1972) "On the Foundations of Poetics. Methodological Prolegomena to a Generative Grammar of Literary Texts", Poetics, 2, 1, 89-123.

Van Oort, R. (2003) "Cognitive Science and the Problem of Representation", Poetics Today, 24, 2, 237-295.

Vartanian, O., Bristol, A. S. y Kaufman, J. C. (eds.), (2013) Neuroscience of creativity, Cambridge (MA), The MIT Press.

Vico, G. (1995) La ciencia nueva, Madrid, Tecnos. 